\title{
5 year incidence of YAG capsulotomy and PCO after cataract surgery with single-piece monofocal intraocular lenses: a real-world evidence study of 20,763 eyes
}

\author{
Paul G. Ursell ${ }^{1} \cdot$ Mukesh Dhariwal $^{2} \cdot$ Derek O'Boyle $^{3} \cdot$ Javeed Khan $^{4} \cdot$ Alessandra Venerus $^{4}{ }^{4}$ \\ Received: 21 January 2019 / Revised: 7 August 2019 / Accepted: 3 September 2019 / Published online: 15 October 2019 \\ (c) The Author(s) 2019. This article is published with open access
}

\begin{abstract}
Objectives To evaluate the 3- and 5-year incidence of posterior capsule opacification (PCO) and neodymium-doped yttrium aluminium garnet (Nd:YAG) capsulotomy in patients following cataract surgery, comparing results for different single-piece acrylic hydrophilic and hydrophobic monofocal intraocular lens (IOL) models and other patient factors.

Patients and methods Electronic medical record data collected from seven United Kingdom (UK) National Health Service (NHS) ophthalmology clinics for routine, age-related ( $\geq 65$ years) cataract surgeries that implanted single-piece acrylic monofocal IOLs during 2010-2013 were used to calculate 3- and 5-year incidence of Nd:YAG and PCO. IOL models of Alcon Acrysof, AMO Tecnis, Bausch \& Lomb (B \& L) Akreos, LenStec Softec, and Rayner Flex were analyzed. Pairwise comparisons were conducted between AcrySof IOLs and other IOLs using Bonferroni adjustment for multiplicity. Multivariate analyses were conducted adjusting for known confounders.

Results The incidence of Nd:YAG capsulotomy ranged between $2.4-12.6 \%$ at 3 years and $5.8-19.3 \%$ at 5 years postcataract surgery. Similarly, the incidence of PCO ranged between $4.7-18.6 \%$ at 3 years and $7.1-22.6 \%$ at 5 years. When comparing all of the single-piece IOLs, AcrySof demonstrated the lowest incidence rates for both PCO and Nd:YAG $(P<0.001$ for each comparison). From adjusted logistic regression analysis, AcrySof were associated with lower 3- and 5 -year odds of Nd:YAG and PCO incidence.

Conclusions Following cataract surgery with single-piece monofocal IOLs different incidence rates of PCO were observed with different IOLs. AcrySof IOLs were associated with significantly lower incidence of PCO requiring Nd:YAG treatment over periods of 3 and 5 years.
\end{abstract}

\section{Introduction}

Posterior capsule opacification (PCO) is the most frequent complication of cataract surgery and can develop soon after to a few years post-procedure [1,2], with incidence figures ranging from $<5 \%$ to as high as $50 \%$ [3]. PCO involves lens epithelial cell growth and proliferation, leading reduced

Mukesh Dhariwal

Mukesh.dhariwal@alcon.com

1 Epsom \& St Helier University Hospitals NHS Trust, Epsom, Surrey, UK

2 Alcon Vision LLC, Fort Worth, TX, USA

3 Alcon Laboratories Ireland Ltd., Cork, Ireland

4 IQVIA, London, UK visual acuity, and may develop in a few months to years following cataract surgery $[4,5]$.

Neodymium-doped yttrium aluminium garnet (Nd:YAG) laser capsulotomy is the only effective surgical treatment for PCO [4], and is a routine and largely safe procedure, but could be associated with occasional complications that include elevated intraocular pressure, retinal detachment, and endophthalmitis [4-6]. The requirement to perform Nd: YAG capsulotomies as a consequence of PCO places a considerable financial burden on healthcare systems. This is due to the costs of the procedure itself, follow-up visits, and also managing the associated complications that may arise as a result of the procedure $[1,2,6]$.

The risk of PCO is understood to be influenced by a number of factors, including edge design, IOL design, haptic design [5], and lens material [7]. While there are known risk factors (such as round vs. sharp edge), more research is needed to understand the role of intraocular lens 
material in PCO risk [8]. Previous studies evaluating the incidence of Nd:YAG capsulotomy in patients with different IOL types suggest that more favourable outcomes have been shown for hydrophobic acrylic lenses compared with those made from other materials, including silicone and hydrophilic acrylic IOLs [9-13].

In long-term observational studies (3-9 years postcataract surgery) looking at the incidence of both PCO and Nd:YAG following cataract surgery, hydrophobic acrylic IOLs have been associated with a longer time until the need for $\mathrm{Nd}: Y A G$ capsulotomy, with less frequent $[9,11,14]$ and less severe [11] or dense [14] PCO, and with lower per-patient post-operative costs [6].

The current study is an extension and post-hoc analysis of a retrospective, real-world evidence cohort study, which examined the impact of IOL biomaterial on PCO and $\mathrm{Nd}$ : YAG capsulotomy at 3 years post-cataract surgery and compared AcrySof IOLs with cohorts of other hydrophobic and hydrophilic IOLs [8]. The objective of this current analysis was to evaluate the long-term incidences of $\mathrm{Nd}$ : YAG and PCO in patients following cataract surgery at 3 and 5 years, comparing results for single-piece acrylic IOLs; and to evaluate 3- and 5-year Nd:YAG and PCO odds ratios based on IOL model and other covariates. Extending the previously published cohort analysis to individual IOL group level analysis provided an opportunity to compare the $\mathrm{Nd}$ :YAG incidence for each IOL, to inform clinical decision making, considering the fact that IOL material or design may affect post-surgery outcomes [7].

Longitudinal real-world evidence studies can supplement clinical insights gained from randomized clinical trials by providing robust long-term outcomes for large cohorts of patients that reflect routine clinical practice and account for real-world conditions, such as multiple patient comorbidities $[15,16]$. Bodies such as the FDA (USA) and NICE (UK) are increasingly relying on real-world evidence to support healthcare decision making [16, 17]. In this analysis, PCO and Nd:YAG incidence were evaluated in various single-piece acrylic IOLs as an extension to the results reported in the 3-year cohort analysis [8].

\section{Materials and methods}

\section{Data source}

As described in the first publication [8], this study was designed as a longitudinal, retrospective cohort study. We sourced electronic medical records (EMRs) data collected from seven UK ophthalmology clinics for routine, agerelated ( $\geq 65$ years) cataract surgeries 2010-2013, and calculated the 3- and 5-year incidence of Nd:YAG capsulotomy and PCO in eyes implanted with acrylic monofocal
IOLs over the follow-up period of 2010-2016. Among this overall study population, single-piece IOLs represented $92 \%$ of the total sample therefore in the present study, we analyzed this largest subgroup ( $>90 \%$ of eyes) of singlepiece IOL models. Patients who died within the (3-year or 5 -year) follow-up period were excluded from the 3 -year and 5 -year analyses, respectively. Table 1 describes the study inclusion and exclusion criteria, and the resulting study population. The National Health Service (NHS) sites for this study were selected on the basis of large numbers of procedures, reliable recording of cataract surgeries and postoperative follow-up data, including records of Nd:YAG capsulotomy and recording of PCO in the Medisoft EMR system. The site selection criteria on usage of Medisoft EMR system was justified because it is a widely used and validated $[18,19]$ EMR system covering $>50 \%$ of NHS, UK cataract clinics, and because the data is highly structured and has the possibility to track patients longitudinally.

\section{Study population}

Eye-level data recorded between January 1, 2010 and December 31, 2016, was extracted for all eyes that had undergone cataract surgery in the selected clinics. Study inclusion criteria: eyes with a record of cataract surgery between January 1, 2010 and December 31, 2013, a record of in-the-bag placement of monofocal IOLs during cataract surgery, details on the type of IOL implanted, age $\geq 65$ years, and $N \geq 500$ for each IOL group to ensure sample parity between treatment groups. For the 5-year follow-up period, only eyes with cataract surgeries performed between 2010 and 2011 were included.

\section{Statistical analyses}

The analysis was carried out in two steps. The first was a pairwise analysis, in which 3- and 5-year incidence of PCO and Nd:YAG capsulotomy were compared by IOL groups (reference group: AcrySof). Incidence proportion was calculated within each group IOL group as the total number of eyes developing the outcome, divided by the total eyes at risk in that group, adjusting therefore for the different groups' size.

The Bonferroni method was used to adjust for multiplicity; four comparisons were carried out, therefore, each comparison was conducted at a level of significance of 0.0125 .

In the second step, an adjusted logistic regression was performed to adjust for other known confounders besides the IOL model (reference group: AcrySof), including age at index, gender, number of eyes operated, intra- and postcataract-surgery complications (e.g. hyphaema, hypotony, 
Table 1 Attrition table based on inclusion/exclusion criteria

\begin{tabular}{|c|c|c|c|c|}
\hline \multirow[t]{2}{*}{ Inclusion criterion } & \multicolumn{2}{|l|}{ Eyes } & \multicolumn{2}{|l|}{ Patients } \\
\hline & $n$ & $\%$ & $n$ & $\%$ \\
\hline Total patients records extracted & & & 178,281 & \\
\hline $\begin{array}{l}\text { Total patients with a record of cataract surgery with single piece, } \\
\text { non-toric, monofocal, acrylic lenses with at least } 500 \text { appearances }\end{array}$ & 160,995 & $100.0 \%$ & 114,740 & $100.0 \%$ \\
\hline Details on monofocal IOL implanted in surgery & 160,685 & $99.8 \%$ & 114,588 & $99.9 \%$ \\
\hline Age $\geq 65$ years on the date of first cataract surgery & 136,911 & $85.0 \%$ & 97,541 & $85.0 \%$ \\
\hline $\begin{array}{l}\text { Excluding capsular tension ring, vitrectomy, or posterior capsule } \\
\text { rupture during cataract surgery }\end{array}$ & 136,610 & $84.9 \%$ & 97,415 & $84.9 \%$ \\
\hline $\begin{array}{l}\text { Excluding patients who had a record of "Vitrectomy", "Previous } \\
\text { pars plana vitrectomy", or "PPV—not specified" as a copathology }\end{array}$ & 135,686 & $84.3 \%$ & 96,670 & $84.3 \%$ \\
\hline $\begin{array}{l}\text { Excluding eyes with }>1 \text { of any type (including minor surgeries) of } \\
\text { surgeries (i.e. patients with }>1 \text { cataract on the same eye) }\end{array}$ & 135,598 & $84.2 \%$ & 96,622 & $84.2 \%$ \\
\hline Eyes operated within the study period 2010-2013 & 48,527 & $30.1 \%$ & 36,703 & $32.0 \%$ \\
\hline $\begin{array}{l}\text { Excluding eyes from patients who died within } 3 \text { years of their index } \\
\text { date (i.e. during their follow-up) }\end{array}$ & 47,754 & $29.7 \%$ & 36,107 & $31.5 \%$ \\
\hline $\begin{array}{l}\text { Excluding eyes from patients who died within } 5 \text { years of their index } \\
\text { date (i.e. during their follow-up) or who had cataract surgery earlier } \\
\text { than } 2011\end{array}$ & 20,763 & $12.9 \%$ & 16,595 & $14.5 \%$ \\
\hline
\end{tabular}

retained soft lens matter), presence of copathologies (e.g. diabetic retinopathy, glaucoma, high myopia), pupil size of the patient, incision site, seniority of surgeon, use of any trypan blue during the surgery, IOL power at index, and best distance-corrected visual acuity (BDVA) at index (per $1 \log$ MAR increase). A stepwise selection process was used with a $5 \%$ level of significance for the covariates selection in the logistic model.

The two outcomes of interest were identified through information recorded in the patients' clinical records; in particular, PCO was identified as any record including "Posterior Capsule Opacification", while Nd:YAG was identified using OPCS code [20] associated with recorded procedures (OPCS-4 code C73.3 + Y08.6, indicating respectively "capsulotomy of posterior lens capsule" and "laser incision of organ").

\section{Results}

The IOLs contributing to this analysis are shown in Table 2.

\section{3- and 5-year incidence of Nd:YAG capsulotomy}

Data from 47,754 eyes contributed to the 3-year follow-up analyses and data from 20,763 eyes contributed to 5-year follow-up analyses.

During the study period, the 3-year incidence of $\mathrm{Nd}$ : YAG was: Alcon AcrySof (2.4\% [307/12,870]; 95\% CI: 2.1-2.6\%), AMO Tecnis (5.1\% [770/15,083]; 95\% CI: 4.8-5.5\%), B\&L Akreos (9.2\% [860/9344]; 95\%
CI: 8.6-9.8\%), Lenstec Softec (12.3\% [770/6274]; 95\% CI: 11.5-13.1\%), and Rayner Flex series (12.6\% [526/4183]; 95\% CI: 11.6-13.6\%) (Fig. 1).

The 5-year incidence of $\mathrm{Nd}: \mathrm{YAG}$ capsulotomy was: Alcon AcrySof (5.8\% [309/5342]; 95\% CI: 5.2-6.4\%), AMO Tecnis (8.5\% [477/5609]; 95\% CI: 7.8-9.2\%), B\&L Akreos (15.2\% [1038/6847]; 95\% CI: 14.3-16.0\%), and Lenstec Softec (19.3\% [573/2964]; 95\% CI: 17.9-20.8\%) (Fig. 1).

\section{3- and 5-year incidence of PCO}

The 3-year incidence of PCO was: Alcon AcrySof (4.7\% [601/12,870]; 95\% CI: 4.3-5.0\%), AMO Tecnis $(7.0 \%$ [1060/15,083]; 95\% CI: 6.6-7.4\%), B\&L Akreos (12.1\% [1135/9344]; 95\% CI: 11.5-12.8\%), Lenstec Softec (16.2\% [1018/6274]; 95\% CI: 15.3-17.1\%), Rayner flex series (18.6\% [777/4,183]; 95\% CI: 17.4-19.8\%) (Fig. 2).

The 5-year incidence of PCO was: Alcon AcrySof (7.1\% [381/5342]; 95\% CI: 6.4-7.8\%), AMO Tecnis (9.9\% [553/ 5609]; 95\% CI: 9.1-10.6\%), B\&L Akreos (17.0\% [1167/ 6847]; 95\% CI: 16.2-17.9\%), Lenstec Softec (22.6\% [669/ 2964]; 95\% CI: 21.1-24.1\%) (Fig. 2).

\section{Adjusted logistical regression analysis}

Odds ratios of $\mathrm{Nd}$ :YAG and $\mathrm{PCO}$ at 3 and 5 years by covariate (including lens type) and obtained from the logistic regression models are shown in Table 3. Similar to the unadjusted incidence calculations, the Alcon AcrySof IOLs were less likely to undergo Nd:YAG or PCO at 3 and 


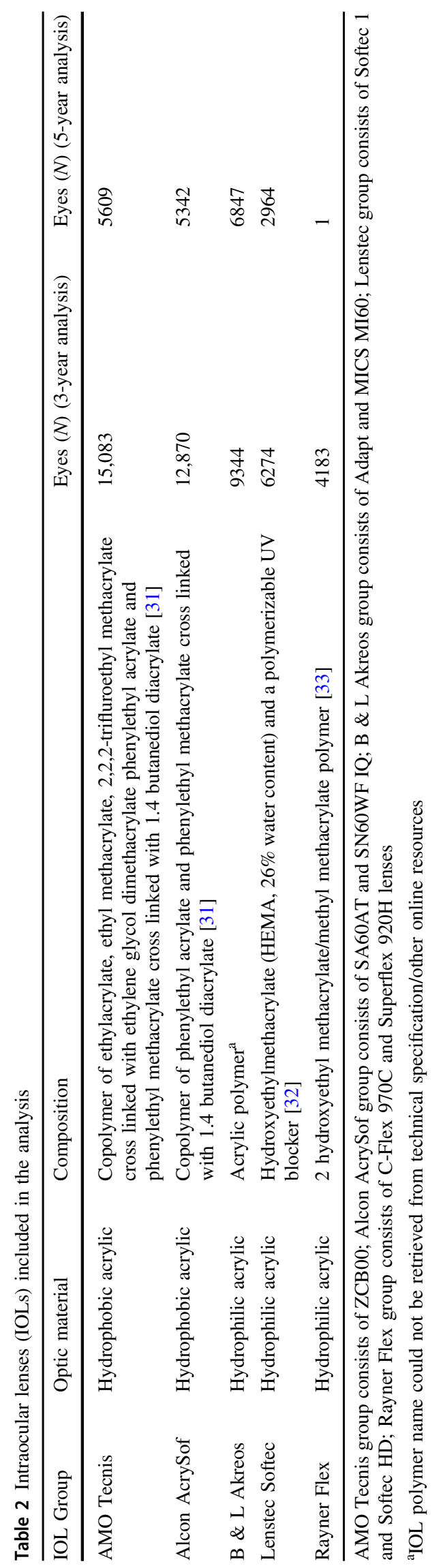

5 years compared with AMO Tecnis, B\&L Akreos, Lenstec Softec, and Rayner Flex series IOLs $(P<0.001$ for each comparison).

The second largest observed impact was in relation to post-operative complications: at 3 years and 5 years, eyes with any post-operative complications were $3.03(P<$ $0.001)$ and $4.76(P<0.001)$ more likely to experience $\mathrm{Nd}$ : YAG; the risk was even higher for PCO, where eyes with post-operative complications were $4.15(P<0.001)$ and 4.5 $(P<0.001)$ more likely to experience this at 3 and 5 years, respectively. In addition, the presence of copathologies recorded up to the data of cataract surgery had a impact on the risk of both PCO and Nd:YAG; at 5 years, eyes with any copathology were $1.22(P<0.001)$ more likely to receive Nd:YAG treatment, and $1.37(P<0.001)$ more likely to experience PCO. Similar trends were observed at 3 years post-cataract surgery.

Additional covariates that appear to increase the risk of Nd:YAG and PCO include younger age, female gender, having cataract surgery on both eyes (rather than one eye only), a lower IOL power at index, and better visual acuity (Table 3).

\section{Discussion}

This study was an extension and post-hoc analysis of a previously published 3-year real-world evidence study [8] performed to collect 3-year and 5-year data on PCO and Nd: YAG incidence with each IOL group in this patient population. To evaluate the effect of IOL materials without the confounding factor of haptic design, this comparison included only single-piece IOLs (data from 47,754 eyes were included in the 3-year follow-up, and data from 20,763 eyes were included in the 5-year follow-up).

Choice of IOL can influence long-term outcomes. This study demonstrates that amongst all the single-piece IOL models implanted at the seven NHS sites, AcrySof IOLs demonstrated the lowest incidence of PCO and Nd:YAG capsulotomy at both 3 and 5 years. These findings remained statistically significant when adjusting for confounding variables.

These results are consistent with those from other longterm, retrospective, real-world studies that compared hydrophobic and hydrophilic IOLs with regards to Nd:YAG and PCO outcomes following cataract surgery $[2,6]$. A 4-year study of German claims data found that hydrophobic IOLs were associated with significantly lower rates of PCO requiring Nd:YAG laser treatment and lower per-patient postoperative costs than hydrophilic IOLs [6]. Similarly, a retrospective study in Sweden (mean follow-up time, 41.5 months) found that hydrophobic IOLs had lower rates of Nd:YAG capsulotomy and PCO, and lower average costs 
(a) 3 years

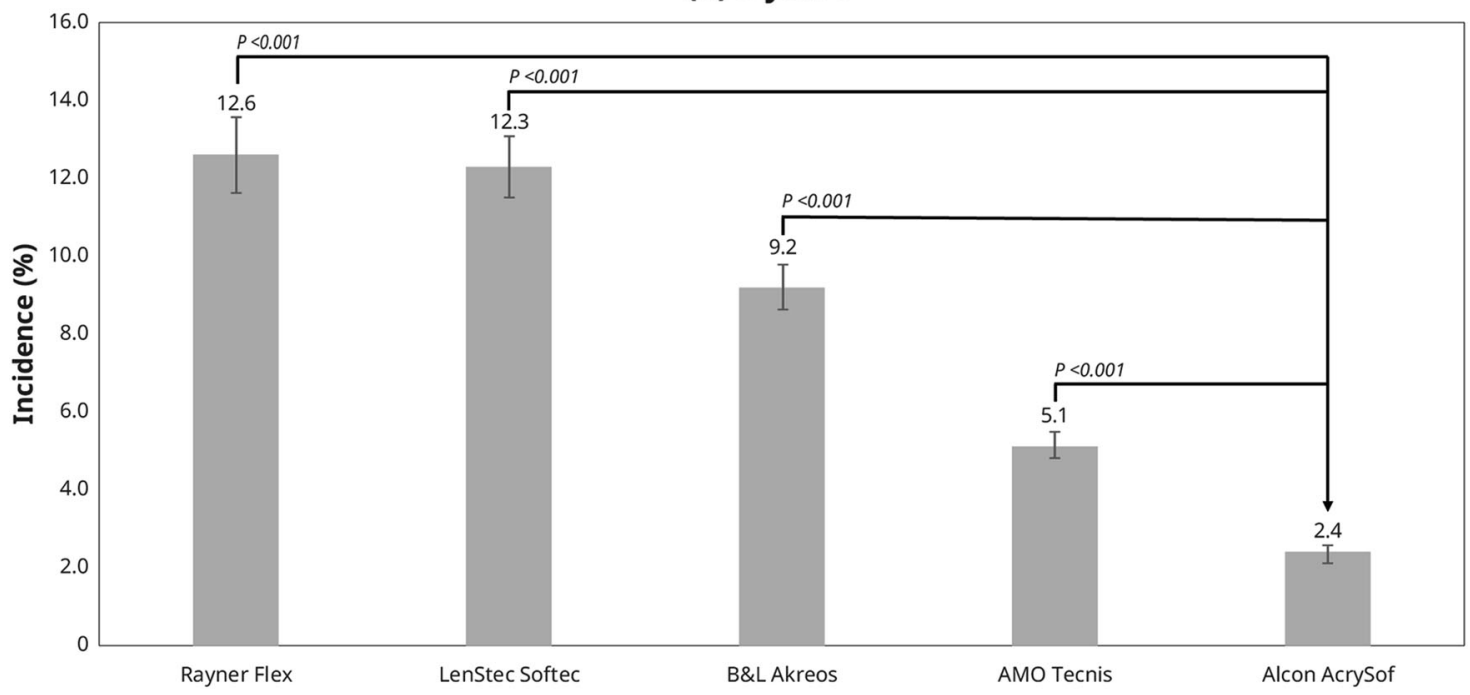

(b) 5 years

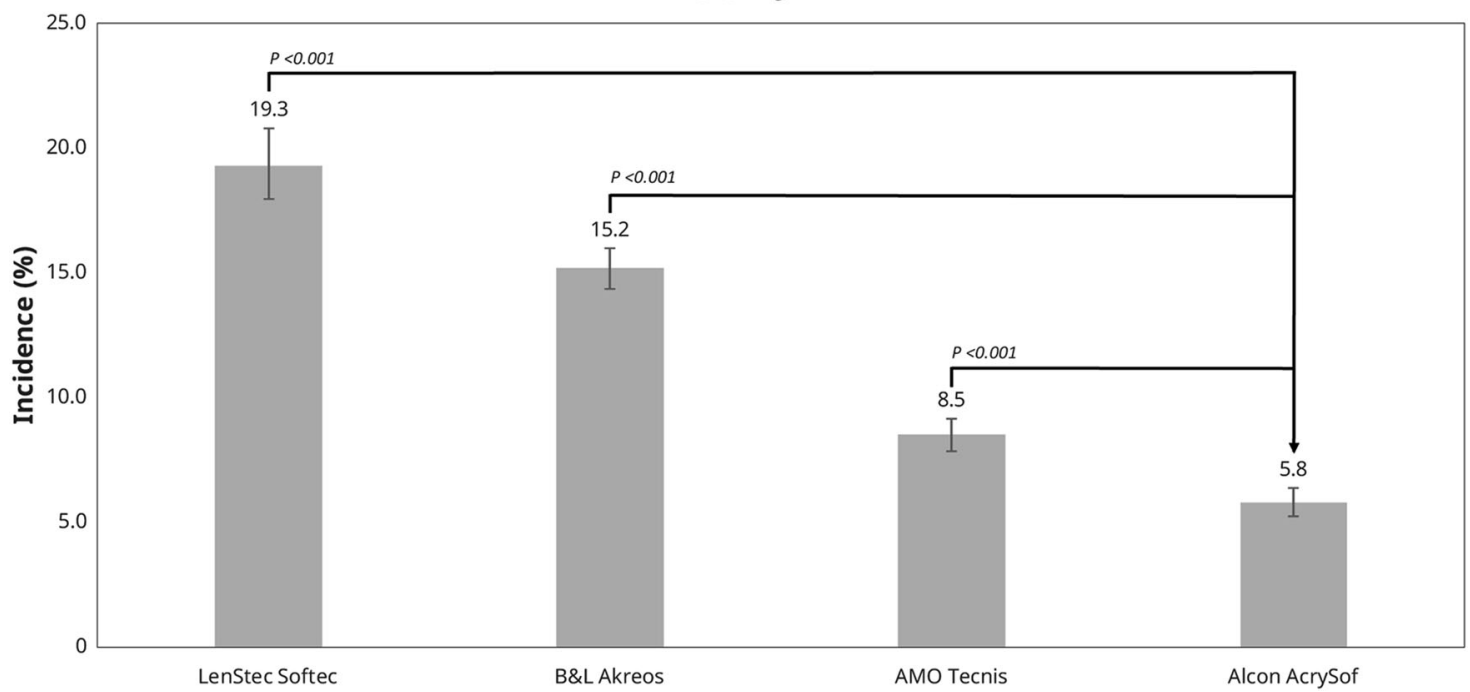

Fig. 1 Incidence of Nd:YAG capsulotomy at 3 years (a) and 5 years (b)

for PCO treatment than hydrophilic IOLs [2]. It has been found that the acrylate material used in AcrySof IOLs shows different fibronectin binding compared with other hydrophobic materials; this may also offer a rationale for the lower PCO and subsequent Nd:YAG rates associated with AcrySof IOLs compared with other IOLs [21].

Edge design has also been shown to provide an important role in development of $\mathrm{PCO}$ and subsequently the risk of $\mathrm{Nd}$ :YAG capsulotomy [5] with previous research [22-28] demonstrating that IOLs with a square-edged optic profile are associated with less PCO than those with a round-edged profile. While all of the IOLs assessed in this study are marketed as having a square-edged profile, it could be the case that the degree of sharpness of the posterior optic edge may have some bearing on the variation in the PCO inhibiting properties displayed by different IOLs [29]. In addition, a study [30] reported that IOLs with a radius of curvature of $<10.0 \mathrm{~mm}$ appear to have good PCO performance.

Our findings also demonstrate that besides IOLs, other factors including patient demographics, presence of other co-pathologies and post-op complications seem to influence long term PCO and Nd:YAG outcomes.

Factors that reduce the rates of PCO and Nd:YAG capsulotomy following cataract surgery are important for improving patient outcomes, as PCO involves loss of clear vision [21], and are likely to contribute to cost savings, as PCO and Nd:YAG represent considerable costs in the management of cataracts $[1,2,6]$. In addition to considering the cost of the Nd:YAG procedure itself, the prevention of 
(a) 3 years

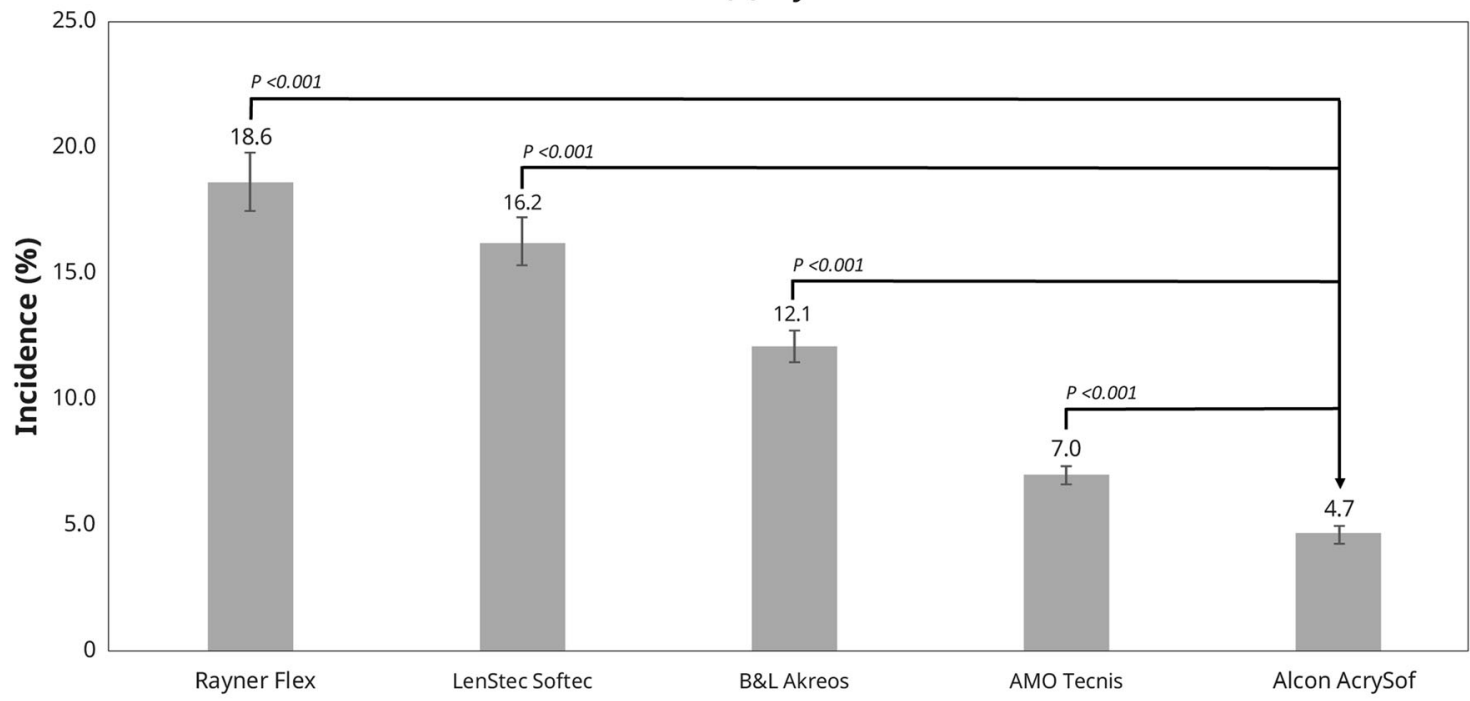

(b) 5 years

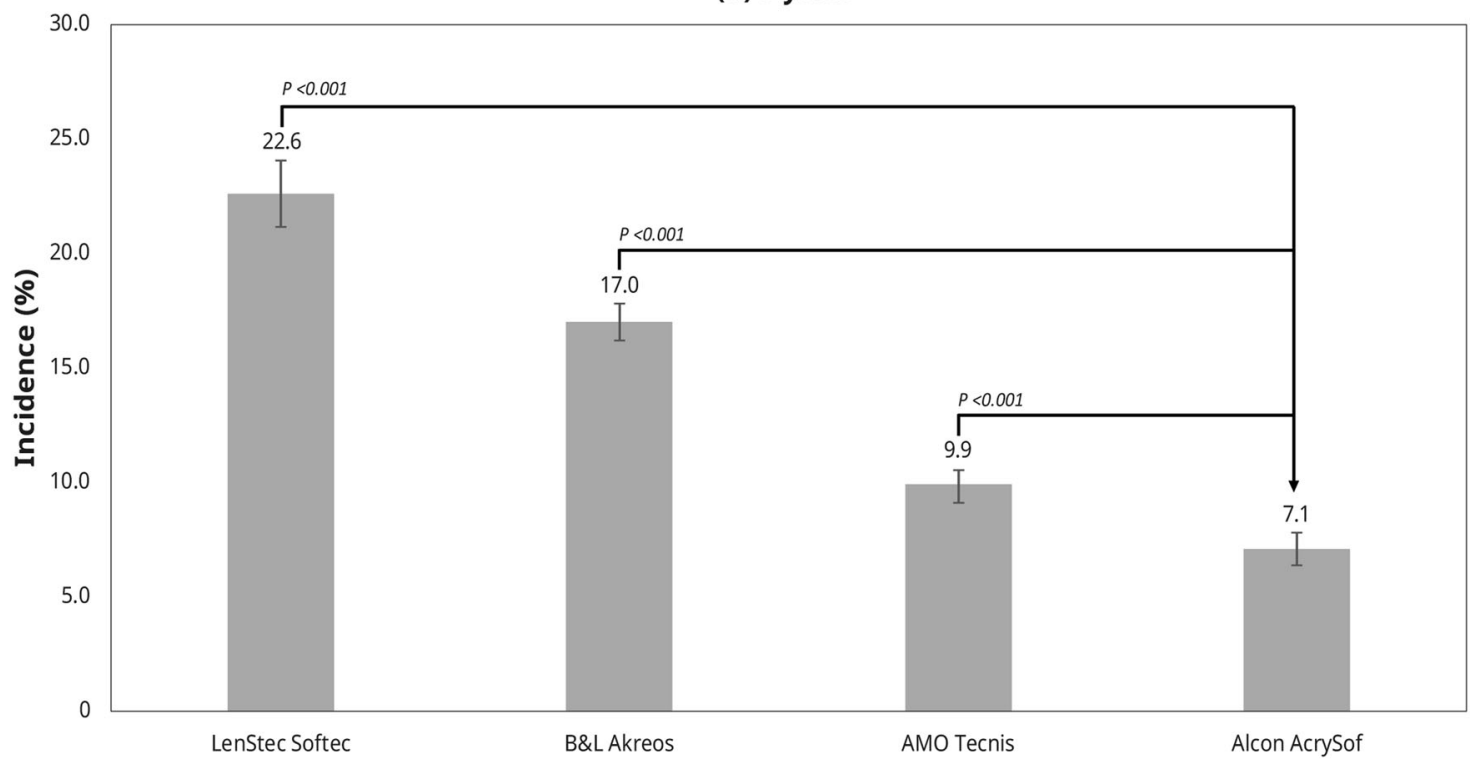

Fig. 2 Incidence of PCO at 3 years (a) and 5 years (b)

PCO and subsequent Nd:YAG capsulotomies could reduce healthcare resource use required for PCO diagnosis, as well as any costs related to post-procedural monitoring, complications, and further treatments.

Strengths of this study include its longitudinal design and large sample size, which provided robust statistical power for comparative analyses; and use of Medisoft EMR data, a validated and widely accepted source of research data. Other important strengths include selection of NHS clinics in this study with completeness of the data collection and consistency of recording by using the Medisoft EMR, which enabled data pooling from multiple sites, and the appropriate statistical methods such as Bonferroni adjustment to account for multiplicity and adjusting for bias by conducting multivariate adjusted logistic regression analysis.

The Medisoft EMR database has comprehensive coverage of patients' ophthalmic clinic related data. However, other relevant healthcare data (e.g. primary care, other secondary care) are not captured, thus reducing visibility of patients' entire medical history a potential limitation and weakness of the study. Other limitations include loss to follow up and missing data (especially with regards to death), which are typical in observational database studies using secondary care data. Due to the lack of an indicator that a patient had de-registered from the hospital or moved to another area, it was assumed in this analysis that if a patient had cataract surgery before 2013, and no record of 


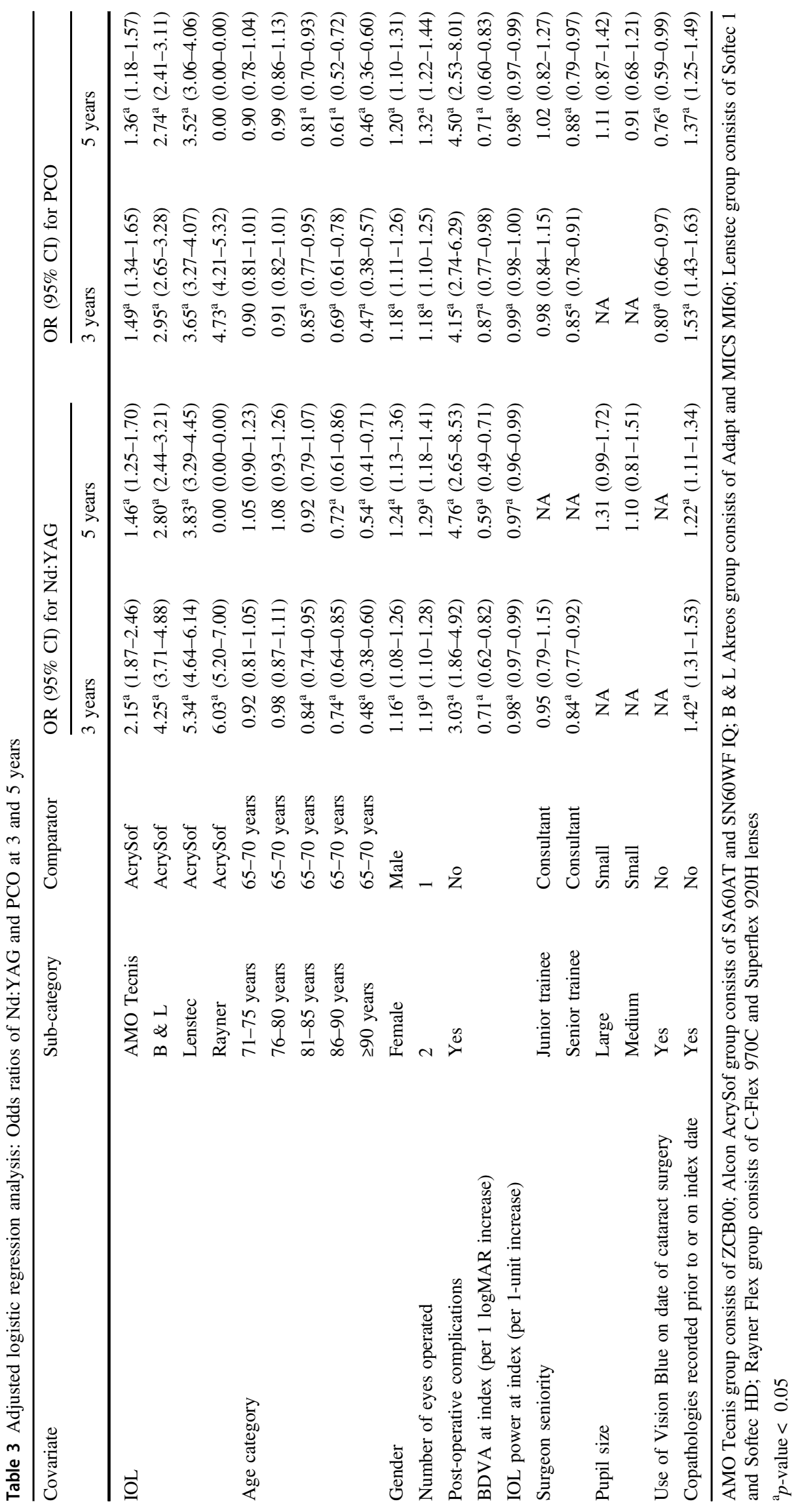


patient death was found, then that patient was assumed to have been followed for at least 3 years ( 5 years if the surgery was done between 2010 and 2011); this could lead to an overestimation of follow-up time, or underestimation of incidence of Nd:YAG and PCO. However, this was assumed to be evenly distributed between the different groups.

This study represents analysis conducted on a large dataset of real-world evidence regarding Nd:YAG and PCO incidence rates evaluated among patients with cataract surgery. Efforts to reduce the incidence of Nd:YAG and PCO following cataract surgery are likely to improve patient visual outcomes, satisfaction, and reduce healthcare resource costs.

In conclusion, this retrospective, real-world evidence study demonstrates that the choice of IOL implanted at the time of cataract surgery plays a considerable role in the risk of developing PCO and subsequent Nd:YAG capsulotomy treatment rates. When comparing all of the single-piece IOLs, AcrySof IOLs are associated with the lowest incidences of PCO and Nd:YAG capsulotomy over follow-up periods of 3 and 5 years post-cataract surgery. Further research is warranted to document the long-term ( $>5$ years) benefits of different IOL materials and design on these outcomes.

\section{Summary}

\section{What was known before}

- The risk of posterior capsule opacification post-cataract surgery is influenced by a number of factors, including edge design, IOL design, haptic design, and lens material

- Choice of IOL can influence long-term outcomes

- Previous studies suggest that more favourable outcomes have been shown for hydrophobic acrylic lenses compared with those made from other materials

\section{What this study adds}

- Our findings demonstrate that besides IOLs, other factors including patient demographics, presence of other co-pathologies, and post-op complications seem to influence long term PCO and Nd:YAG outcomes

- AcrySof IOLs were associated with significantly lower incidence of PCO requiring Nd:YAG treatment over periods of 3 and 5 years

- This study included a very large population of over 20,000 eyes undergoing cataract surgery, thus providing robust statistical analyses
Acknowledgements The authors would like to thank all the NHS sites which contributed data for this research and Katarina Majirska at Alcon, Anushini Muthutantri at IQVIA, and Christian Martin at Medisoft for their help with the study.

Funding This study was sponsored by Alcon Vision LLC (Fort Worth, Texas, USA). Alcon is the market authorisation holder of AcrySof IOLs. IQVIA received financial support from Alcon.

\section{Compliance with ethical standards}

Conflict of interest The authors have no proprietary or commercial interest in any materials discussed in this article. MD and DO'B are employees of Alcon, the study sponsor. JK and AV are employees of IQVIA, the company contracted by Alcon to conduct the study. PGU received consulting fees and travel grant from Alcon.

Publisher's note Springer Nature remains neutral with regard to jurisdictional claims in published maps and institutional affiliations.

Open Access This article is licensed under a Creative Commons Attribution 4.0 International License, which permits use, sharing, adaptation, distribution and reproduction in any medium or format, as long as you give appropriate credit to the original author(s) and the source, provide a link to the Creative Commons license, and indicate if changes were made. The images or other third party material in this article are included in the article's Creative Commons license, unless indicated otherwise in a credit line to the material. If material is not included in the article's Creative Commons license and your intended use is not permitted by statutory regulation or exceeds the permitted use, you will need to obtain permission directly from the copyright holder. To view a copy of this license, visit http://creativecommons. org/licenses/by/4.0/.

\section{References}

1. Boureau C, Lafuma A, Jeanbat V, Smith AF, Berdeaux G. Cost of cataract surgery after implantation of three intraocular lenses. Clin Ophthalmol. 2009;3:277-85.

2. Cullin F, Busch T, Lundstrom M. Economic considerations related to choice of intraocular lens (IOL) and posterior capsule opacification frequency-a comparison of three different IOLs. Acta Ophthalmol. 2014;92:179-83.

3. Raj SM, Vasavada AR, Johar SR, Vasavada VA, Vasavada VA. Post-operative capsular opacification: a review. Int J Biomed Sci. 2007;3:237-50.

4. American Academy of Ophthalmology. Nd:YAG laser posterior capsulotomy. https://www.aao.org/munnerlyn-laser-surgery-center/ ndyag-laser-posterior-capsulotomy-3. Accessed 04 Nov 2013.

5. Perez-Vives C. Biomaterial influence on intraocular lens performance: an overview. J Ophthalmol. 2018;2018:2687385.

6. Kossack N, Schindler C, Weinhold I, Hickstein L, Lehne M, Walker J, et al. German claims data analysis to assess impact of different intraocular lenses on posterior capsule opacification and related healthcare costs. J Public Health. 2018;26:81-90.

7. NICE. Cataracts in adults: management. Full guideline. United Kingdom: NICE; 2017. https://www.nice.org.uk/guidance/ng77/ evidence/full-guideline-pdf-4655997901.

8. Ursell PG, Dhariwal M, Majirska K, Ender F, Kalson-Ray S, Venerus A, et al. Three-year incidence of Nd:YAG capsulotomy and posterior capsule opacification and its relationship to 
monofocal acrylic IOL biomaterial: a UK real world evidence study. Eye. 2018;32:1579-89.

9. Auffarth GU, Brezin A, Caporossi A, Lafuma A, Mendicute J, Berdeaux G. Comparison of Nd:YAG capsulotomy rates following phacoemulsification with implantation of PMMA, silicone, or acrylic intra-ocular lenses in four European countries. Ophthalmic Epidemiol. 2004;11:319-29.

10. Vasavada AR, Praveen MR. Posterior capsule opacification after phacoemulsification: annual review. Asia Pac J Ophthalmol. 2014;3:235-40.

11. Ernest PH. Posterior capsule opacification and neodymium: YAG capsulotomy rates with AcrySof acrylic and PhacoFlex II silicone intraocular lenses. J Cataract Refract Surg. 2003;29:1546-50.

12. Ursell PG, Spalton DJ, Pande MV, Hollick EJ, Barman S, Boyce $\mathrm{J}$, et al. Relationship between intraocular lens biomaterials and posterior capsule opacification. J Cataract Refract Surg. 1998;24:352-60.

13. Hollick EJ, Spalton DJ, Ursell PG, Pande MV, Barman SA, Boyce $\mathrm{JF}$, et al. The effect of polymethylmethacrylate, silicone, and polyacrylic intraocular lenses on posterior capsular opacification 3 years after cataract surgery. Ophthalmology. 1999;106:49-54.

14. Chang A, Kugelberg M. Posterior capsule opacification 9 years after phacoemulsification with a hydrophobic and a hydrophilic intraocular lens. Eur J Ophthalmol. 2017;27:164-8.

15. de Lusignan S, Crawford L, Munro N. Creating and using realworld evidence to answer questions about clinical effectiveness. J Innov Health Inform. 2015;22:368-73.

16. FDA. Use of real-world evidence to support regulatory decisionmaking for medical devices. Guidance for Industry and Food and Drug Administration Staff. U.S.: FDA; 2017. https://www.fda. gov/downloads/medicaldevices/deviceregulationandguidance/ guidancedocuments/ucm513027.pdf.

17. NICE Decision Support Unit. The use of real world data for the estimation of treatment effects in NICE decision making. Report by the Decision Support Unit; 2016. Sheffield, United Kingdom. http://nicedsu.org.uk/wp-content/uploads/2018/ 05/RWD-DSU-REPORT-Updated-DECEMBER-2016.pdf.

18. Day AC, Donachie PH, Sparrow JM, Johnston RL. The Royal College of Ophthalmologists' National Ophthalmology Database study of cataract surgery: Report 1; visual outcomes and complications. Eye. 2015;29:552-60.

19. Jackson TL, Donachie PH, Sparrow JM, Johnston RL. United Kingdom National Ophthalmology Database Study of Vitreoretinal
Surgery: Report 1; case mix, complications, and cataract. Eye. 2013;27:644-51.

20. OPCS classification of interventions and procedures, version 4.7 volume II. 2014. London: TSO. ISBN 9780113229918

21. Ong M, Wang L, Karakelle M. Fibronectin adhesive properties of various intraocular lens materials. Investig Ophthalmol Vis Sci. 2013;54:819.

22. Petrash JM. Aging and age-related diseases of the ocular lens and vitreous body. Investig Ophthalmol Vis Sci. 2013;54:54-9.

23. Nishi O, Nishi K, Wickstro"m K. Preventing lens epithelial cell migration using intraocular lenses with sharp rectangular edges. J Cataract Refract Surg. 2000;26:1543-9.

24. Nishi O, Nishi K. Preventing posterior capsule opacification by creating a discontinuous sharp bend in the capsule. J Cataract Refract Surg. 1999;25:521-6.

25. Peng Q, Visessook N, Apple DJ, et al. Surgical prevention of posterior capsule opacification. Part 3: intraocular lens optic barrier effect as a second line of defense. J Cataract Refract Surg. 2000;26:198-213.

26. Hayashi K, Hayashi H. Posterior capsule opacification in the presence of an intraocular lens with a sharp versus rounded optic edge. Ophthalmology. 2005;112:1550-6.

27. Nagamoto T, Eguchi G. Effect of intraocular lens design on migration of lens epithelial cells onto the posterior capsule. J Cataract Refract Surg. 1997;23:866-72.

28. Tetz M, Wildeck A. Evaluating and defining the sharpness of intraocular lenses: part 1: influence of optic design on the growth of the lens epithelial cells in vitro. J Cataract Refract Surg. 2005;31:2172-9.

29. Nanavaty MA, Zukaite I, Salvage J. Edge profile of commercially available square edged intraocular lenses: Part 2. J Cataract Refract Surg. 2019;45:847-53.

30. Nanavaty MA, Spalton DJ, Boyce J, Brain A, Marshall J. Edge profile of commercially available square-edged intraocular lenses. J Cataract Refractive Surg. 2008;34:677-86.

31. Werner L. Glistenings and surface light scattering in intraocular lenses. J Cataract Refractive Surg. 2010;36:1398-420.

32. Espandar L, Sikder S, Moshirfar M. Softec HD hydrophilic acrylic intraocular lens: biocompatibility and precision. Clin Ophthalmol. 2011;5:65-70.

33. Rayner Intraocular Lenses Ltd. /Rayner Surgical Inc. C-flex 570C IFU Device description. United Kingdom. https://www.accessda ta.fda.gov/cdrh_docs/pdf6/p060011c.pdf 